\title{
Article \\ Genes Associated with Foliar Resistance to Septoria Nodorum Blotch of Hexaploid Wheat (Triticum aestivum L.)
}

\author{
Dora Li ${ }^{1}$, Esther Walker ${ }^{1,2}$ and Michael Francki 1,2,* \\ 1 State Agricultural Biotechnology Centre, Murdoch University, South St, Murdoch, WA 6150, Australia; \\ D.Li@murdoch.edu.au (D.L.); esther.walker@murdoch.edu.au (E.W.) \\ 2 Department of Primary Industries and Regional Development, 3 Baron Hay Ct, \\ South Perth, WA 6151, Australia \\ * Correspondence: michael.francki@dpird.wa.gov.au
}

Citation: Li, D.; Walker, E.; Francki, M. Genes Associated with Foliar Resistance to Septoria Nodorum Blotch of Hexaploid Wheat (Triticum aestivum L.). Int. J. Mol. Sci. 2021, 22, 5580. https://doi.org/10.3390/ ijms 22115580

Academic Editor: Sukhwinder Singh

Received: 1 May 2021

Accepted: 22 May 2021

Published: 25 May 2021

Publisher's Note: MDPI stays neutra with regard to jurisdictional claims in published maps and institutional affiliations.

Copyright: (c) 2021 by the authors. Licensee MDPI, Basel, Switzerland. This article is an open access article distributed under the terms and conditions of the Creative Commons Attribution (CC BY) license (https:// creativecommons.org/licenses/by/ $4.0 /)$.

\begin{abstract}
The genetic control of host response to the fungal necrotrophic disease Septoria nodorum blotch (SNB) in bread wheat is complex, involving many minor genes. Quantitative trait loci (QTL) controlling SNB response were previously identified on chromosomes 1BS and 5BL. The aim of this study, therefore, was to align and compare the genetic map representing QTL interval on 1BS and 5BS with the reference sequence of wheat and identify resistance genes ( $R$-genes) associated with SNB response. Alignment of QTL intervals identified significant genome rearrangements on 1BS between parents of the DH population EGA Blanco, Millewa and the reference sequence of Chinese Spring with subtle rearrangements on 5BL. Nevertheless, annotation of genomic intervals in the reference sequence were able to identify and map 13 and $12 R$-genes on $1 \mathrm{BS}$ and 5BL, respectively. $R$-genes discriminated co-located QTL on 1BS into two distinct but linked loci. NRC1a and TFIID mapped in one QTL on 1BS whereas RGA and Snn1 mapped in the linked locus and all were associated with SNB resistance but in one environment only. Similarly, Tsn1 and WK35 were mapped in one QTL on 5BL with NETWORKED $1 A$ and RGA genes mapped in the linked QTL interval. This study provided new insights on possible biochemical, cellular and molecular mechanisms responding to SNB infection in different environments and also addressed limitations of using the reference sequence to identify the full complement of functional $R$-genes in modern varieties.
\end{abstract}

Keywords: septoria nodorum blotch (SNB); wheat; quantitative trait loci (QTL); resistance; international wheat genome sequencing Consortium (IWGSC)

\section{Introduction}

Septoria nodorum blotch (SNB) is a fungal disease of wheat caused by the necrotrophic pathogen Parastagonospora (syn. ana, Stagonospora; teleo, Phaeosphaeria) nodorum (Berk.). Symptoms of infection on the leaf include lens-shaped red-brown lesions surrounded by a yellow halo that coalesce to form blotches with pycnidia evident in time. Disease symptoms on glumes include dark brown to purple with ash-grey areas embedded with black pycnidia, and become apparent following distinct symptoms on leaves. SNB can cause significant yield loss of up to $12.9 \%$ in Western Australia (WA) [1] due to the reduced photosynthetic capacity caused by infection in the leaves and glume [2-4].

Reducing SNB severity in adult plants is important when the disease is at its greatest in-season risk during warmer spring conditions in WA. Therefore, a number of studies have focused on evaluating SNB response of bi-parental homozygous populations and global germplasm collections in WA environments to unravel the genetic basis of adult plant resistance [5-7]. Analysis of bi-parental mapping populations detected similar quantitative trait loci (QTL) in successive years in WA on chromosomes 1B and 2A [6] and 2D [5-7], whereas environment-specific QTL were detected on 4B, 5A and 5B [5,6]. Significant genotype-by-environment-by-isolate interactions causing variable disease response was 
further supported when a collection of 232 global wheat accessions were evaluated in multiple environments in WA using genome-wide association study (GWAS) [7]. A comparison of genetic response to SNB infection in Nordic wheat confirmed genotype-by-environment interactions and environment-specific QTL in other regions of the world under natural disease infection [8-10]. Alternative host genes, infection by genetically diverse isolates with variability in virulence or aggressiveness, or a combination of factors may cause different SNB responses of wheat genotypes when evaluated in different environments [7].

Knowledge on biological mechanisms involved with SNB response has been limited until recently when studies identified genetic and biochemical interactions between host and pathogen. Parastagonospora nodorum produces a range of necrotrophic effector (NE) proteins with an inverse gene-for-gene relationship with the host contributing towards plant necrosis [11]. There are a range of NEs discovered with corresponding sensitivity loci mapped in wheat including SnToxA-Tsn1 interaction on chromosome 5B $[12,13]$, SnTox1-Snn1 on 1B [14,15], SnTox2-Snn2 on 2D [13], SnTox3-Snn3-B1 on 5B [16,17], SnTox4Snn4 on 1A [18], SnTox5-Snn5 on 4B [19], SnTox6-Snn6 on 6A [20] and SnTox7-Snn7 on $2 \mathrm{D}$ [21]. The relationship between $\mathrm{NE}$ and disease response in multiple environments was realized through a comparison of chromosomal map locations for NE-Snn loci and QTL. The association of $T s n 1$ locus, for example, was environment-specific [6,7,22], indicating that specific SnTox-Snn interactions may have limited influence in controlling disease progression in some environments. Similar inferences were made in GWAS analysis when known Snn loci were in linkage equilibrium with QTL for foliar and glume response in several environments $[7,10]$. The limited influence of known NE-Snn interactions regulating SNB response in different environments was perpetuated from field evaluation in Norway, the United Kingdom and the eastern region of the US [10,23]. Therefore, it appears that host genes other than known $S n n$ and Tsn 1 loci contribute towards disease response against different isolates and environments.

Despite known NE-Snn interactions being disparate with SNB disease development across multiple environments and diverse isolates [7,9,10,23], the cloning of Tsn1 and Snn1 genes provided initial insights into biological mechanisms underpinning response to NE and/or SNB disease. The protein translated by Tsn1 has typical disease resistance features including serine threonine protein kinase and nucleotide binding site-C-terminal leucine rich repeat (NBS-LRR) domains [24], whereas Snn1 encodes a wall-associated kinase (WK) [15]. These genes and the corresponding proteins are presumed to exploit plant defence mechanisms resembling effector-triggered immunity (ETI) and pathogenassociated molecular pattern (PAMP)-triggered immunity (PTI) [25]. The proteins are thought to hijack signalling pathways for resistance to biotrophic pathogens rendering susceptibility of the host to SNB infection [15,26]. It is feasible, however, that P. nodorum infection can also exploit other aspects of ETI/PTI pathways or, indeed, alternative host defence mechanisms. Various biochemical and cellular components provide alternative biological targets for necrotrophs to penetrate host defences and elicit a disease response during pathogen invasion [27].

Whilst chromosome walking and physical assembly was used to clone Tsn1 and Snn1, the release of a high-quality reference sequence for wheat $[28,29]$ may expedite discovery of other genes responding to SNB. Coverage of up to $94 \%$ of a reference genome sequence of hexaploid wheat from the experimental line Chinese Spring and subsequent annotation identified 104,091-107,891 protein coding genes $[29,30]$ but did not necessarily represent an absolute value of gene copy number across bread wheat cultivars. Copy number variants $(\mathrm{CNV})$, presence-absence variants (PAV) and single nucleotide polymorphisms (SNP) contributed towards genomic differences amongst modern wheat cultivars with an average of $>128,500$ genes per cultivar estimated from pan-genome sequencing [31,32]. Despite structural variation in genomes across wheat cultivars, the public availability of a reference genome provides an initial basis to discover genes and alleles that may underpin trait variation. 
The aim of this study, therefore, was to align and compare the genetic map representing QTL interval for SNB foliar resistance on chromosome 1BS and 5BL $[6,33]$ with the physical map and identify resistance genes (R-genes) associated with SNB response. Doing so will identify similarities or structural differences between QTL intervals for EGA Blanco, Millewa and the reference sequence, with potential for discovery of alternative genes and proteins of PTI/ETI other than the known genes Snn1 and Tsn1 or other biological pathways. Identification of genes encoding proteins with similarity to disease resistance genes ( $R$-genes) having significant association with SNB response would provide wider insight into biological pathways involved in SNB response and their interactions with different isolates and environmental cues.

\section{Results}

2.1. Alignment of Genetic and Physical Maps and Gene Annotation on Chromosomes $1 B S$ and 5BL

The genetic maps with QTL on chromosomes 1BS and 5BL [33] were aligned to the IWGSC reference sequence (Gramene release \#62, November 2019) using DNA sequence identity of mapped SNP markers. The genetic order of markers within and flanking the QTL interval on chromosome 1BS did not align with the physical order of genes with small intrachromosomal translocations apparent between the genomes of EGA Blanco, Millewa and the reference genome sequence (Figure 1A).

A

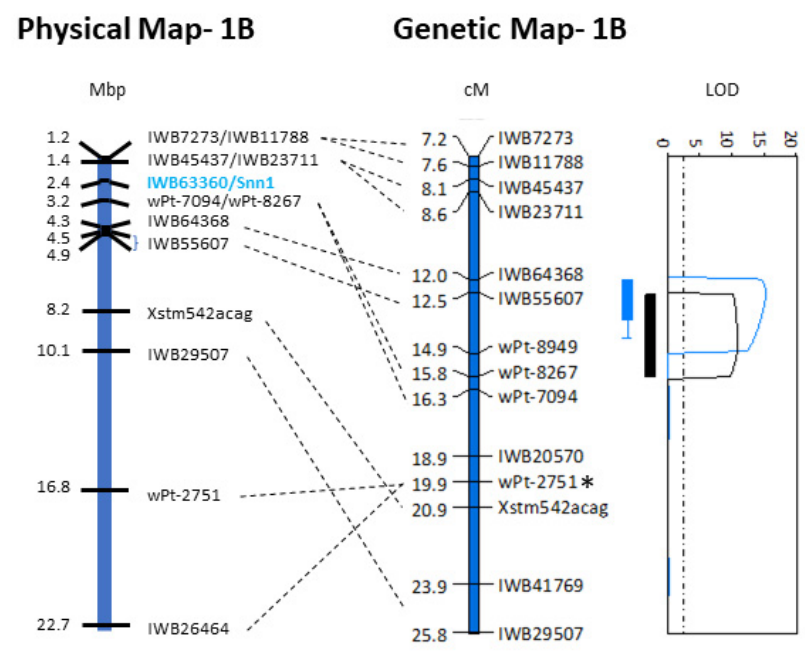

B

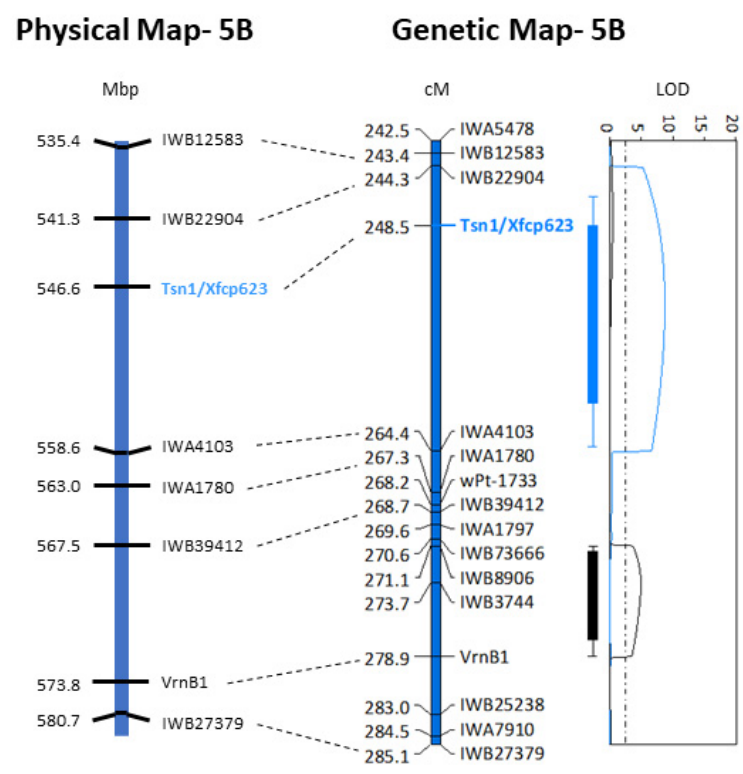

Figure 1. Alignment of the physical and genetic maps for QTL on chromosomes (A) 1BS and (B) 5BL. QTL traces on 1BS with corresponding LOD scores for foliar disease scores in 2007 (blue bar and lines) and in 2008 (black bar and lines) as previously reported $[6,33]$ are shown to the right of each figure. Alignment of SNP markers within and flanking each QTL between the genetic map (in centimorgan distances, $\mathrm{cM}$ ) and the reference sequence (in megabase pair distances, Mbp) are shown with dashed black lines. The asterisk denotes DArT marker co-segregating with SNP marker IWB26464. Markers for Snn1 and $T s n 1$ are indicated in blue.

Analysis of the physical region on 1BS, therefore, was extended beyond the QTL delineated by markers $w P t-8267$ (SNP at 1,825,338 bp) and IWB64368 (SNP at 4,320,856 bp) to include markers IWB7273 (SNP at 1,203,968 bp) and IWB26464 (SNP at 22,701,051 bp) in the reference genome (Figure 1A) to account for potential $R$-gene content flanking the interval in the reference genome but may be represented within the QTL in the genetic map. Annotation of the $21.5 \mathrm{Mbp}$ region on 1BS identified a total of 423 genes with 122 having significant identity with proteins encoded by $R$-genes in the reference sequence (Supplementary Table S1). Interestingly, multiple copies of $R$-gene families were apparent 
in the $21.5 \mathrm{Mbp}$ region, which included NRC (3 copies), RPM1 (25 copies), Lr21 (3 copies), Pm3 (9 copies), LRR (26 copies) and RPP13 (27 copies) (Supplementary Table S1). Furthermore, the gene TraesCS1B02G004100.1 at 2,354,630 bp had 100\% amino acid identity with Snn1 gene known to be involved with SNB response (Supplementary Table S1). It is evident, therefore, the targeted region on chromosome 1BS contained highly duplicated members of $R$-gene families interspersed amongst other low copy defence response and non-disease related sequences in the reference sequence of Chinese Spring with apparent rearrangements compared with the genomes of EGA Blanco and Millewa. Annotation of disease and non-disease related genes, their physical location including and encoded amino acid residues and identity with annotated proteins is provided in Supplementary Table S1.

The genetic map of chromosome 5BL that harboured two environment-specific QTL for SNB $[6,33]$ was aligned to the physical map using flanking SNP markers IWB12583 (SNP at 539,072,424 bp) and IWB27379 (SNP at 580,686,141 bp) (Figure 1B). Markers with a physical location in the reference genome sequence were congruent with genetic map position indicating no substantial gene or genome rearrangements for this region in EGA Blanco or Millewa (Figure 1B). Moreover, the genetic distance of $41.7 \mathrm{cM}$ between IWB12583 and IWB27379 encompassing the two QTL for SNB resistance represented a physical distance of $45.6 \mathrm{Mbp}$ (Figure 1B) containing 448 genes with their physical location on the Chinese Spring reference genome provided in Supplementary Table S1. A total of 39 genes were annotated as having significant identity with proteins encoded by $R$-genes or wall-associated kinase genes known to be involved with disease response. Some multigene families were identified on chromosome 5BL, including two copies having identity with known disease resistance genes RPP13, RPM1, Lr10 and peroxidase (Per), four copies of $L R R$ and 11 copies of wall-associated kinases (WAK) (Supplementary Table S1). The remaining $16 R$-genes were $\mathrm{r}$ single copy within the $45.6 \mathrm{Mbp}$ region (Supplementary Table S1). Interestingly, annotation of the $41.7 \mathrm{cM}$ physical region on 5BL did not identify the location of the Tsn1 gene involved in NE interactions [24], confirming that this gene was missing within the QTL interval of the Chinese Spring reference genome.

\subsection{Genes on Chromosome 1BS Associated with Foliar SNB Resistance}

Members of $R$-gene families (Supplementary Table $\mathrm{S} 1$ ) were specifically selected at regular intervals spanning the $21.5 \mathrm{Mbp}$ region, alleles identified either through PAV or from gene re-sequencing and subsequent markers genetically mapped to refine QTL regions associated with foliar SNB response to a smaller physical region. The smaller intervals were subsequently used to target further $R$-genes within the QTL. PCR primers for tiling paths were designed from a total of $62 R$-genes extracted from the reference genome representing members of RPP13, RPM1, NRC, Pm3 and Lr21, RGA, LRR and $R R$ gene families (Supplementary Table S1). Collectively, 27 genes were polymorphic and markers were developed based on PAV and mapped in the EGA Blanco/Millewa population (Table 1; Figure 2A).

The remaining 35 selected genes had neither amplicon size differences nor DNA sequence polymorphism between parental varieties, and therefore were presumed not to be associated with SNB response. Analogous to the iSelect Infinium 90K markers used to align genetic and physical maps (Figure 1A), genetic order for 27 R-gene loci did not align with physical order (Table 1; Supplementary Table S1). Assuming the physical sequence assembled in Gramene Release \#62 is accurate, it appears that $R$-gene translocations were apparent on chromosome 1BS between genomes of EGA Blanco and Millewa compared with the reference sequence from Chinese Spring. 
Table 1. Markers derived from annotated $R$-genes within the $21.5 \mathrm{Mbp}$ QTL interval from the reference sequence and mapped to chromosome 1BS in the EGA Blanco/Millewa DH population. Physical position of gene annotations and the genetic map position of $R$-gene markers are shown.

\begin{tabular}{|c|c|c|c|c|}
\hline Marker & IWGSC ID & Polymorphism ${ }^{a}$ & $\begin{array}{l}\text { Physical Map Position } \\
\text { (bp) })^{b}\end{array}$ & $\begin{array}{c}\text { Genetic Map Position } \\
\text { (cM) }\end{array}$ \\
\hline 1BR_NRC_5A & TraesCS1B02G002400.1 & PAV (EGA Blanco) & $1,782,029$ & 7.7 \\
\hline $1 B \_N R C \_A 1$ & TraesCS1B02G002800.1 & PAV (EGA Blanco) & $1,846,624$ & 14.4 \\
\hline 1BR_RPP13_1B & TraesCS1B02G002900.1 & PAV (EGA Blanco) & $1,943,148$ & 14.4 \\
\hline $1 B R \_R P P 13 \_2 C$ & TraesCS1B02G003000.1 & PAV (EGA Blanco) & $1,971,915$ & 14.4 \\
\hline 1BR_RGA_4B & TraesCS1B02G003100.1 & PAV (EGA Blanco) & $2,004,576$ & 14.4 \\
\hline 1BR_RPP13_11D & TraesCS1B02G003200.1 & PAV (EGA Blanco) & $2,057,816$ & 10.4 \\
\hline 1BR_RPP13_13E & TraesCS1B02G003300.1 & PAV (EGA Blanco) & $2,078,761$ & 10.9 \\
\hline 1BR_RPP13_7F & TraesCS1B02G003400.1 & PAV (EGA Blanco) & $2,105,792$ & 10.4 \\
\hline 1B_RGA_E1 & TraesCS1B02G004100.1 & PAV (EGA Blanco) & $2,357,713$ & 14.9 \\
\hline 1B_NRC_C1 & TraesCS1B02G004600.1 & PAV (EGA Blanco) & $2,756,985$ & 14.9 \\
\hline 1BR_RR_3A & TraesCS1B02G004700.1 & PAV (EGA Blanco) & $2,919,258$ & 14.4 \\
\hline 1BR_LRR_3C & TraesCS1B02G004900.1 & PAV (EGA Blanco) & $3,145,388$ & 14.0 \\
\hline 1BR_RR_2C & TraesCS1B02G005600.1 & PAV (Millewa) & $3,656,683$ & 7.2 \\
\hline 1B_Lr21_B3 & TraesCS1B02G006300.1 & PAV (Millewa) & $3,925,448$ & 7.2 \\
\hline 1BR_LRR_1D & TraesCS1B02G006400.1 & PAV (Millewa) & $3,935,573$ & $4.0^{*}$ \\
\hline 1BR_LRR_4E & TraesCS1B02G006800.1 & PAV (Millewa) & $3,966,850$ & 7.7 \\
\hline 1B_RPM1_A1 & TraesCS1B02G006900.1 & PAV (Millewa) & $4,049,415$ & 6.8 \\
\hline 1BR_LRR_2F & TraesCS1B02G007200.1 & PAV (Millewa) & $4,534,576$ & 7.7 \\
\hline 1BR_LRR_4G & TraesCS1B02G007300.1 & PAV (Millewa) & $4,146,127$ & $0 *$ \\
\hline IWB64368 & TraesCS1B02G007800.1 & SNP & $4,320,651$ & 9.8 \\
\hline 1BR_LRR_1H & TraesCS1B02G008500.1 & PAV (Millewa) & $4,483,578$ & 7.7 \\
\hline 1BR_LRR_1I & TraesCS1B02G008800.1 & PAV (Millewa) & $4,534,869$ & 7.7 \\
\hline 1BR_LRR_4J & TraesCS1B02G008900.1 & PAV (Millewa) & $4,541,238$ & 7.7 \\
\hline 1B_Pm3_F1 & TraesCS1B02G051200.1 & PAV (Millewa) & $6,272,172$ & 24.8 \\
\hline 1B_RPP13_C1 & TraesCS1B02G014500.1 & PAV (EGA Blanco) & $7,040,210$ & 28.1 \\
\hline 1B__Pm3_D1 & TraesCS1B02G014800.1 & PAV (EGA Blanco) & $7,257,001$ & 25.2 \\
\hline 1B_Pm3_D6 & TraesCS1B02G014900.1 & PAV (Millewa) & $7,253,228$ & 26.6 \\
\hline 1B_Pm3_I1 & TraesCS1B02G042500.1 & PAV (Millewa) & $22,155,020$ & 42.5 \\
\hline
\end{tabular}

${ }^{a}$ Marker polymorphism represented by presence/absence variation (PAV) or single nucleotide polymorphism (SNP). Absence of marker (null-allele) in parental variety is shown in brackets; ${ }^{\mathrm{b}}$ physical position of tile from where marker was designed; * marker with segregation distortion. Critical chi-square value $>10 \%$ (1 degree freedom).

The co-located QTL on chromosome 1BS, QSn107.daw-1B and QSnl08.daw-1B, assumed that the same gene controlled SNB foliar resistance in different environments $[6,33]$. The genetic linkage map consisting of SNP markers from the iSelect 90K genotyping array [33] were integrated with markers developed from $R$-genes in this study and subsequent QTL analysis confirmed two distinct and environment-specific QTL from field phenotyping data in 2007 and 2008 (Figure 2A). Therefore, 1BS contained several genes at two loci that responded independently to SNB. Genes TraesCS1B02G002400.1 with identity to NBS-LRR REQUIRED FOR HYPERSENSITIVE RESPONSE-ASSOCIATED CELL DEATH 1 (NRC 1a; AKC34064.1) (Supplementary Table S1) represented by the marker 1BR_NRC_5A (Table 2) and TraesCS1B02G007800.1 having identity with a The Transcription Initiation Factor sub-unit II (TFIID; EMT21817.1) (Supplementary Table S1) represented by the SNP marker IWB64368 (Table 2 ) had highly significant $(p<0.001$ ) association with QSnl07.daw-1B by way of LOD scores of 13.6 and 18.6, respectively (Table 2; Figure 2A). 


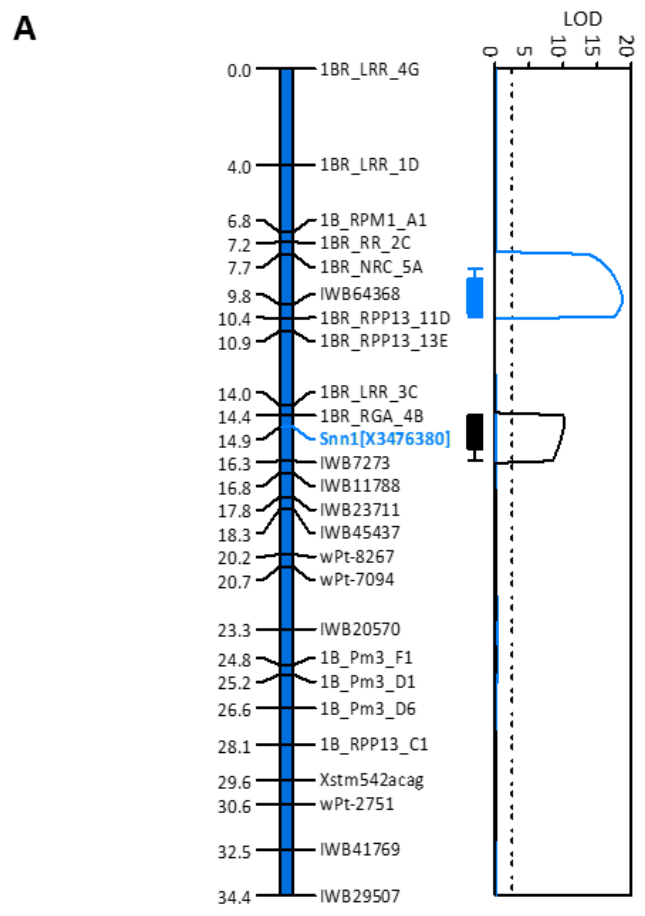

B

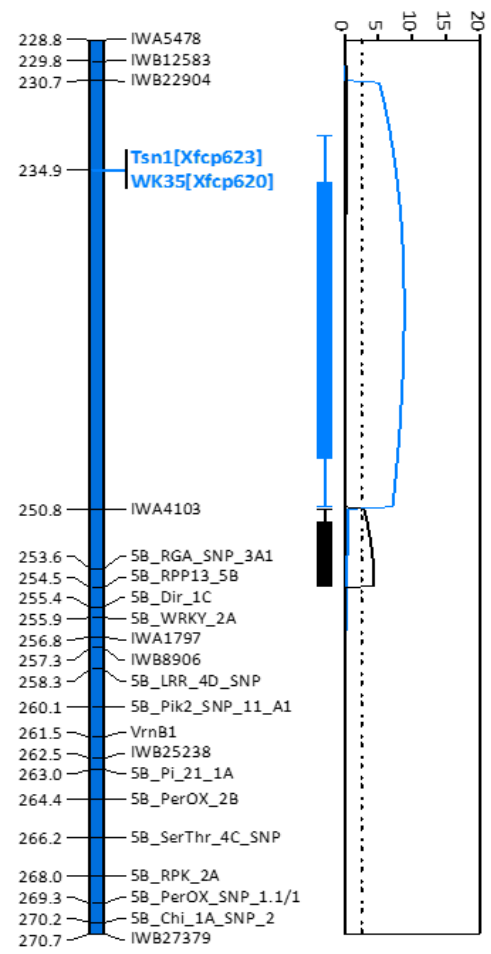

Figure 2. Genetic map of $R$-gene markers developed in this study integrated with genetic map of SNP and other markers [33] for chromosomes (A) 1BS and (B) 5BL. Markers for Snn1, Tsn1 and WK35 genes are highlighted in blue. QTL traces with corresponding LOD scores for foliar disease scores in 2007 (blue bar and lines) and in 2008 (black bar and lines) on 1BS and 5BL as previously reported [33] are shown to the right of each figure.

Table 2. One-dimension scanning positions of $R$-gene markers associated with QTL for SNB resistance in a DH population derived from the cross of resistant and susceptible parents, EGA Blanco and Millewa, respectively. Gene markers with significant associations $(p<0.001)$ are highlighted in grey shading.

\begin{tabular}{|c|c|c|c|c|c|c|c|}
\hline QTL & Marker (Gene) & Polymorphism ${ }^{a}$ & $\begin{array}{c}\text { Physical } \\
\text { Position (bp) }\end{array}$ & $\begin{array}{c}\text { Genetic } \\
\text { Position (cM) }\end{array}$ & $\operatorname{LOD}^{d}$ & PVE $^{\text {e }}$ & Additive $^{\mathrm{f}}$ \\
\hline \multirow{5}{*}{ QSnl07.daw-1B } & 1BR_RR_2C & PAV (Millewa) & $3,656,683$ & 7.2 & 0.1 & 0.1 & 0.4 \\
\hline & 1BR_NRC_5A & PAV (EGA Blanco) & $1,782,029$ & 7.7 & 13.6 & 20.3 & -5.9 \\
\hline & $I \overline{W B} B 43 \overline{6} 8$ & SNP & $4,320,856$ & 9.8 & 18.6 & 25.8 & -6.7 \\
\hline & 1BR_RPP13_11D & PAV (EGA Blanco) & $2,057,816$ & 10.4 & 0.0 & 0.0 & 0.0 \\
\hline & 1BR_RPP13_13E & PAV (EGA Blanco) & $2,078,761$ & 10.9 & 0.0 & 0.0 & 0.0 \\
\hline \multirow{5}{*}{ QSnl08.daw-1B } & 1BR_LRR_3C & PAV (EGA Blanco) & $3,145,388$ & 14.0 & 0.0 & 0.0 & 0.1 \\
\hline & 1BR_RGA_4B & PAV (EGA Blanco) & $2,004,576$ & 14.4 & 10.0 & 16.9 & -3.9 \\
\hline & $\begin{array}{l}\text { X3476283 * } \\
(\text { Snn1) }\end{array}$ & PAV (EGA Blanco) & $2,357,713$ & 14.9 & 10.1 & 17.1 & -3.9 \\
\hline & IWB7273 & SNP & $1,203,706$ & 16.3 & 0.0 & 0.0 & -0.1 \\
\hline & IWB11788 & SNP & $1,203,968$ & 16.8 & 0.0 & 0.0 & -0.1 \\
\hline \multirow{6}{*}{ QSnl07.daw-5B } & IWB12583 & SNP & $539,072,791$ & 229.8 & 0.1 & 0.2 & 0.5 \\
\hline & IWB22904 & SNP & $541,343,146$ & 230.7 & 0.1 & 0.1 & 0.4 \\
\hline & Xfcp623 (Tsn1) & PAV & ND & 234.9 & 7.5 & 10.1 & -4.2 \\
\hline & $\begin{array}{l}X f c p 620 \\
(W A K 35)\end{array}$ & PAV & $546,568,033$ & 234.9 & 7.5 & 10.1 & -4.2 \\
\hline & IWA4103 & SNP & $558,625,387$ & 250.8 & 0.6 & 0.7 & -1.1 \\
\hline & 5B_RGA_SNP_3A1 & SNP & $562,793,027$ & 253.6 & 0.4 & 0.4 & -0.9 \\
\hline
\end{tabular}


Table 2. Cont.

\begin{tabular}{|c|c|c|c|c|c|c|c|}
\hline QTL & Marker (Gene) & Polymorphism ${ }^{\text {a }}$ & $\begin{array}{c}\text { Physical } \\
\text { Position (bp) }\end{array}$ & $\begin{array}{c}\text { Genetic } \\
\text { Position }(\mathrm{cM})^{\mathrm{c}}\end{array}$ & LOD $^{d}$ & PVE $^{\mathrm{e}}$ & Additive $^{\mathrm{f}}$ \\
\hline \multirow{6}{*}{ QSnl08.daw-5B } & $X f c p 623(T s n 1)$ & PAV & ND & 234.9 & 0.3 & 0.5 & -0.6 \\
\hline & $\begin{array}{c}X f c p 620 \\
(W A K 35)\end{array}$ & PAV & $546,568,033$ & 234.9 & 0.3 & 0.5 & -0.6 \\
\hline & IWA4103 & SNP & $558,625,387$ & 250.8 & 2.8 & 4.6 & -2.0 \\
\hline & 5B_RGA_SNP_3t & SNP & $562,793,027$ & 253.6 & 4.3 & 6.9 & -2.4 \\
\hline & 5B_RPP13_5B & PAV (Millewa) & $563,121,363$ & 254.5 & 0.0 & 0.0 & 0.0 \\
\hline & 5B_Dir_1C & PAV (Millewa) & $570,174,000$ & 255.4 & 0.0 & 0.0 & 0.0 \\
\hline
\end{tabular}

a Marker polymorphism represented by Presence/Absence Variation (PAV) or Single Nucleotide Polymorphism (SNP). Absence of gene (null-allele) in parental variety is shown in brackets; ${ }^{\mathrm{b}}$ International Wheat Genome Sequencing Consortium (IWGSC) RefSeq v1.0, bp: base pairs; ${ }^{c}$ genetic map position derived from the EGA Blanco/Millewa doubled haploid mapping population [33] in centimorgan (cM) distances; ${ }^{\mathrm{d}}$ logarithm of the odds; ${ }^{\mathrm{e}}$ percentage variation of the phenotype explained in the doubled haploid mapping population; ${ }^{\mathrm{f}}$ positive and negative effects indicate the allele was inherited from the male (Millewa) and the female (EGA Blanco) parent, respectively;

* diagnostic marker for Snn1.

Neither of the genes, however, were associated $(p>0.05)$ with QSnl08.daw-1B (Figure 2A), indicating that their contribution to SNB response was specific to the 2007 environment. Instead, gene TraesCS1B02G003100.1 with identity to a putative Resistance Gene Analogue (RGA; KAE8799430.1) represented by 1BR_RGA_4B, and Snn1 (TraesCS1B02G0041 00.1) represented by X3476283 (2.35 Mbp) (Supplementary Table S1), had highly significant association $(p<0.001)$ with QSnl08.daw-1B, with LOD scores of 10.0 and 10.1 , respectively (Table 2; Figure 2A). Therefore, two genes up to $2.54 \mathrm{Mbp}$ apart on chromosome $1 \mathrm{BS}$ had significant association with SNB resistance in each environment.

\subsection{Genes on Chromosome 5BL Associated with Foliar SNB Resistance}

Similar to the analysis of genes on chromosome 1BS, $R$-genes were selected at regular intervals spanning the $45.6 \mathrm{Mbp}$ region on chromosome 5BL, mapped and further genes identified in Gramene Release\#62 from within refined QTL region. A total of 39 genes in the $45.6 \mathrm{Mbp}$ region encoding proteins with highest similarity to disease resistance and wall-associated kinases were analysed for allele differences, either by amplicon size differences or SNP discovery (Supplementary Table S1). There were six annotated $R$-genes with either amplicon size difference or SNP between parental varieties EGA Blanco and Millewa (Table 3).

QTL mapping using the genetic map with ordered $R$-genes showed two distinct regions for SNB resistance on chromosome 5BL detected when the DH population was evaluated for SNB foliar response in 2007 and 2008. The position of QTL (Figure 2B) were similar to that previously reported $[6,33]$. One-dimensional scanning positions of genes associated with QTL identified Xfcp620 (WK35) and Xfcp623 (Tsn1) at the same genetic locus (Table 2; Figure 2B), having a significant association $(p<0.001)$ with SNB resistance with a LOD score of 7.5 when the population was evaluated in 2007 (Table 2). However, neither WK35 nor Tsn1 were associated with SNB response in 2008 (Table 2). Instead, the SNP marker IWA4103 at 558.62 Mbp representing gene TraesCS5B02G380700.1 encoding a NETWORKED 1A protein (XP_003577773.1) (Supplementary Table S1) and 5B_RGA_SNP_3A1 at $562.79 \mathrm{Mbp}$ representing gene TraesCS5B02G383800.1 encoding a putative RGA (XP_020196799.1) (Supplementary Table S1) had significant $(p<0.001)$ associations with SNB resistance (LOD scores of 2.8 and 4.3, respectively) when evaluated in 2008 (Table 2). Therefore, it appears that at least three genes in addition to Tsn1 on chromosome 5BL are associated with SNB infection, but in different environments.

The remaining genes showed no DNA sequence polymorphism and were therefore not further considered to be associated with SNB resistance. The markers Xfcp623 and Xfcp620, representing Tsn1 and cell wall-associated kinase (WK35) genes, respectively [24], were also mapped at $234.9 \mathrm{cM}$ (Table 3) despite the former gene not being represented in the physical interval of $45.6 \mathrm{Mbp}$ on $5 \mathrm{~B}$ of the wheat genome reference sequence. The 14 genes with PAV or SNP were assigned to the EGA Blanco/Millewa genetic map and 
the genetic order between $234.9 \mathrm{cM}$ and $270.2 \mathrm{cM}$ (Figure 2B) aligned with the physical map between $546.56 \mathrm{Mbp}$ and $589.16 \mathrm{Mbp}$ of the reference genome sequence from Chinese Spring (Table 3).

Table 3. Markers derived from annotated R-genes within the $45.6 \mathrm{Mbp}$ QTL interval from the reference sequence and mapped to chromosome 5BL in the EGA Blanco/Millewa DH population. Physical position of gene annotations and the genetic map position of $R$-gene markers are shown.

\begin{tabular}{ccccc}
\hline Marker & IWGSC ID & Polymorphism & $\begin{array}{c}\text { Physical Map Position } \\
\text { (bp) } \mathbf{b}\end{array}$ & $\begin{array}{c}\text { Genetic Map Position } \\
\text { (cM) }\end{array}$ \\
\hline Xfcp623 & ND c & PAV (EGA Blanco) & ND $^{\text {c }}$ & 234.9 \\
Xfcp620 & TraesCS5B02G368200.1 & SNP & $546,568,033$ & 234.9 \\
IWA4103 & TraesCS5B02G380700.1 & SNP & $558,625,387$ & 250.8 \\
5B_RGA_SNP_3A1 & TraesCS5B02G383800.1 & SNP & $562,793,027$ & 253.6 \\
5B_RPP13_5B & TraesCS5B02G384300.1 & PAV (Millewa) & $563,121,363$ & 254.5 \\
5B_WRKY_2A & TraesCS5B02G384600.1 & PAV (EGA Blanco) & $563,332,765$ & 255.9 \\
5B_Dir_1C & TraesCS5B02G391000.1 & PAV (Millewa) & $570,174,000$ & 255.4 \\
5B_LRR_4D_SNP & TraesCS5B02G393400.1 & SNP & $571,609,010$ & 258.3 \\
5B_PiK2_SNP_11_A1 & TraesCS5B02G394100.1 & SNP & $571,998,218$ & 260.1 \\
5B_Pi_21_1A & TraesCS5B02G396100.1 & PAV (EGA Blanco) & $573,141,867$ & 263 \\
5B_RPK_2A & TraesCS5B02G402100.1 & PAV (Millewa) & $578,607,490$ & 268 \\
5B_SerThr_4C_SNP & TraesCS5B02G403300.1 & SNP & $580,085,277$ & 266.2 \\
5B_PerOX_2B & TraesCS5B02G404300.1 & PAV (EGA Blanco) & $580,431,388$ & 264.4 \\
5B_PerOX_SNP_1.1 & TraesCS5B02G404200.1 & SNP & $580,431,742$ & 269.3 \\
5B_Chi_1A_SNP_2 & TraesCS5B02G403700.1 & SNP & $589,164,993$ & 270.2 \\
\hline
\end{tabular}

a Polymorphism represented by presence/absence variation (PAV) or single nucleotide polymorphism (SNP) between wheat cultivars EGA Blanco and Millewa. Absence of marker (null-allele) in parental variety is shown in brackets; ${ }^{b}$ physical position of tile from where marker was designed; ${ }^{c}$ ND: sequence not identified in the targeted QTL interval of the physical map in the IWGSC reference genome sequence of Chinese Spring.

\subsection{Gene Structure Analysis}

A structural comparison of genes associated with SNB resistance on chromosomes $1 \mathrm{BS}$ and 5BL was carried out to reveal differences that could explain variable SNB response between EGA Blanco and Millewa. The annotation of four genes retrieved from the genome assembly of chromosome 1BS and associated with SNB response in one of two environments and subsequent design of tiling paths provided opportunities to re-sequence and identify alleles from cultivars EGA Blanco and Millewa (Figure 3).

No tiling paths from NRC1a, RGA and Snn1 amplified PCR products from the SNB susceptible cultivar, Millewa, whereas most tiling paths for the TFIID gene were able to be amplified from the resistant cultivar, EGA Blanco (Figure 3). It is assumed, therefore, that gene loss in the QTL for SNB foliar response on chromosome 1BS was apparent in the genome of cultivars EGA Blanco and Millewa compared to Chinese Spring. Amplification of tiling paths from $S n n 1$ of cultivar Millewa showed identical exon and intron size with the corresponding gene in the reference genome. The remaining genes, however, either showed near complete intron-exon structure (TFIID) or partial gene sequence (NRC1a and $R G A$ ) (Figure 3) due to the inability to amplify specific tiling paths based on primers designed against corresponding genes from the Chinese Spring reference genome. Therefore, deletion, or significant gene sequence variation, is apparent on EGA Blanco and Millewa residing within the QTL interval on chromosome 1BS.

The four candidate $R$-genes having significant association with foliar SNB response on chromosome 5BL were amplified and characterized from EGA Blanco and Millewa. All tiling paths from NETWORK1A and RGA genes were amplified from both EGA Blanco and Millewa with similar exon sizes to those extracted from the reference genome (Figure 4). 


\section{A}

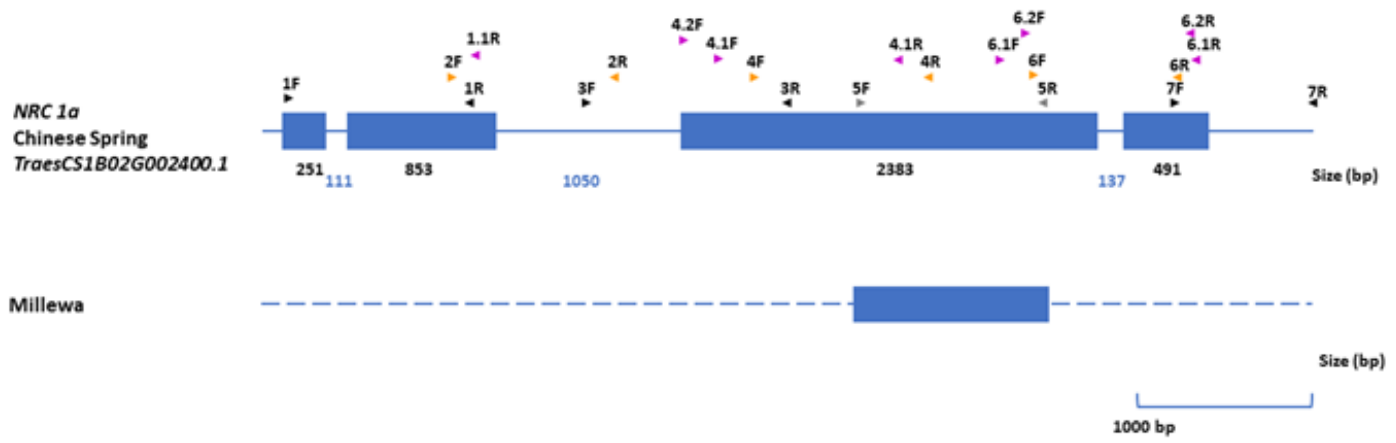

B
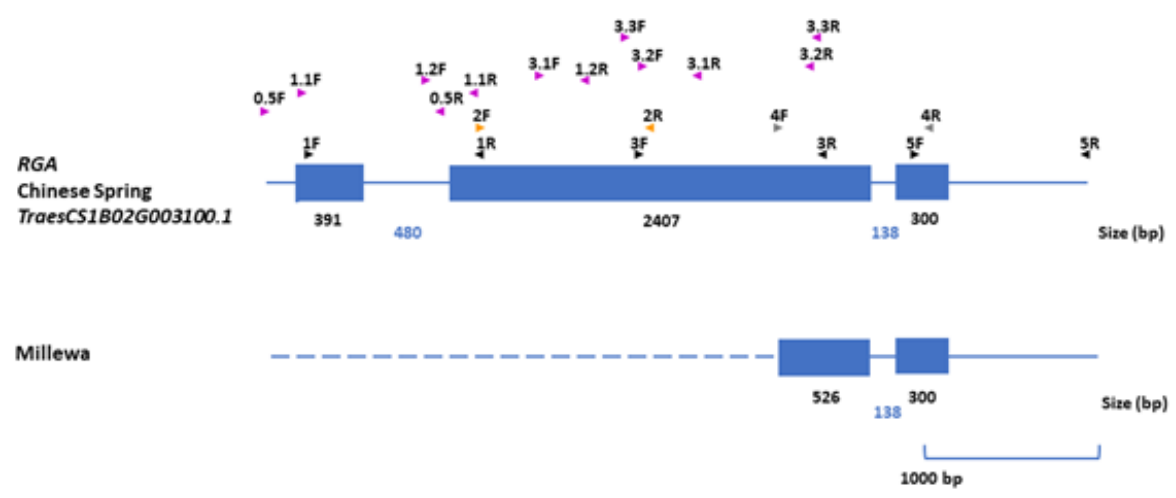

\section{C}

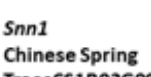

TraesCS1B026004100.1

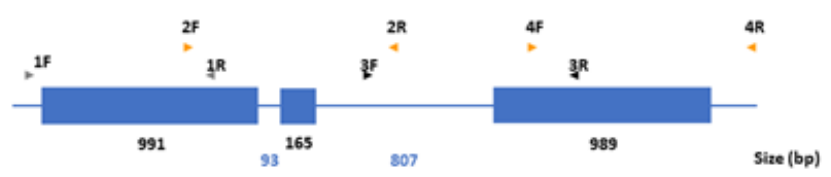

Millewa
(MW686896)

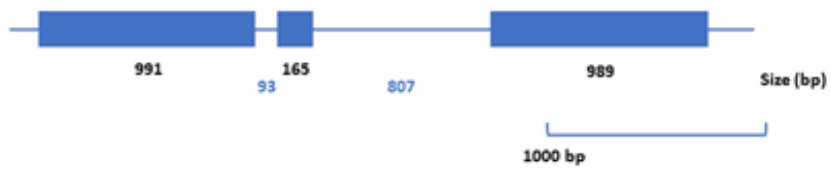

D

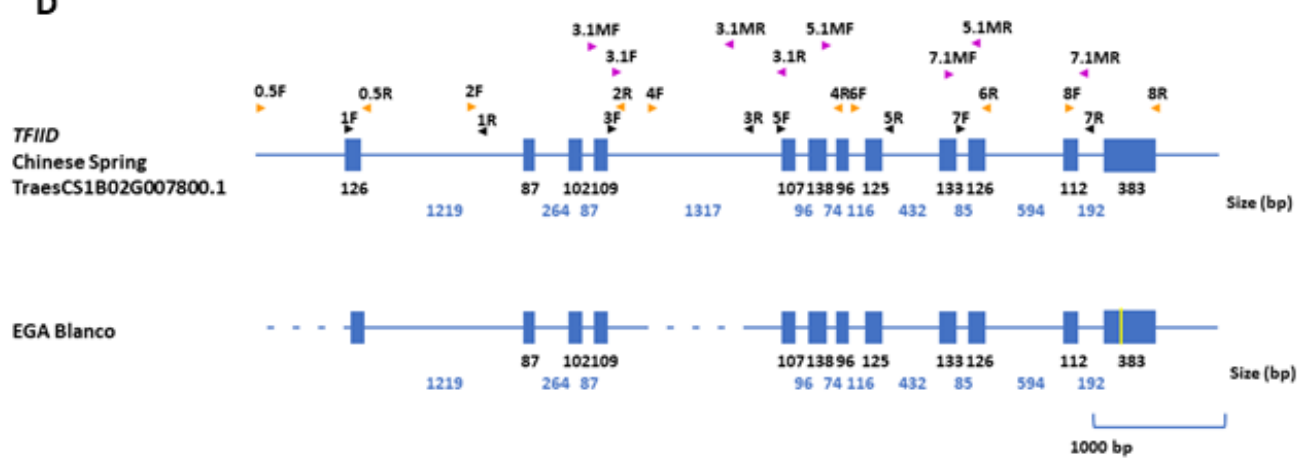

Figure 3. Gene structure for (A) NRC1a, (B) RGA, (C) Snn1 and (D) TFIID on chromosome 1BS from reference sequence and varieties. Blue lines and boxes represent introns and exons, respectively, for annotated genes from the reference sequence. Position of PCR primers for amplifying tiling paths from varieties are shown above gene structure from the Chinese Spring reference sequence. Size of introns and exons are shown in base pairs (bp). Dashed blue lines represent regions where tiling paths were unable to be amplified in corresponding varieties. Yellow lines represent SNP between Chinese Spring and varieties. Genbank accession numbers for complete annotated genes are provided in parentheses. 

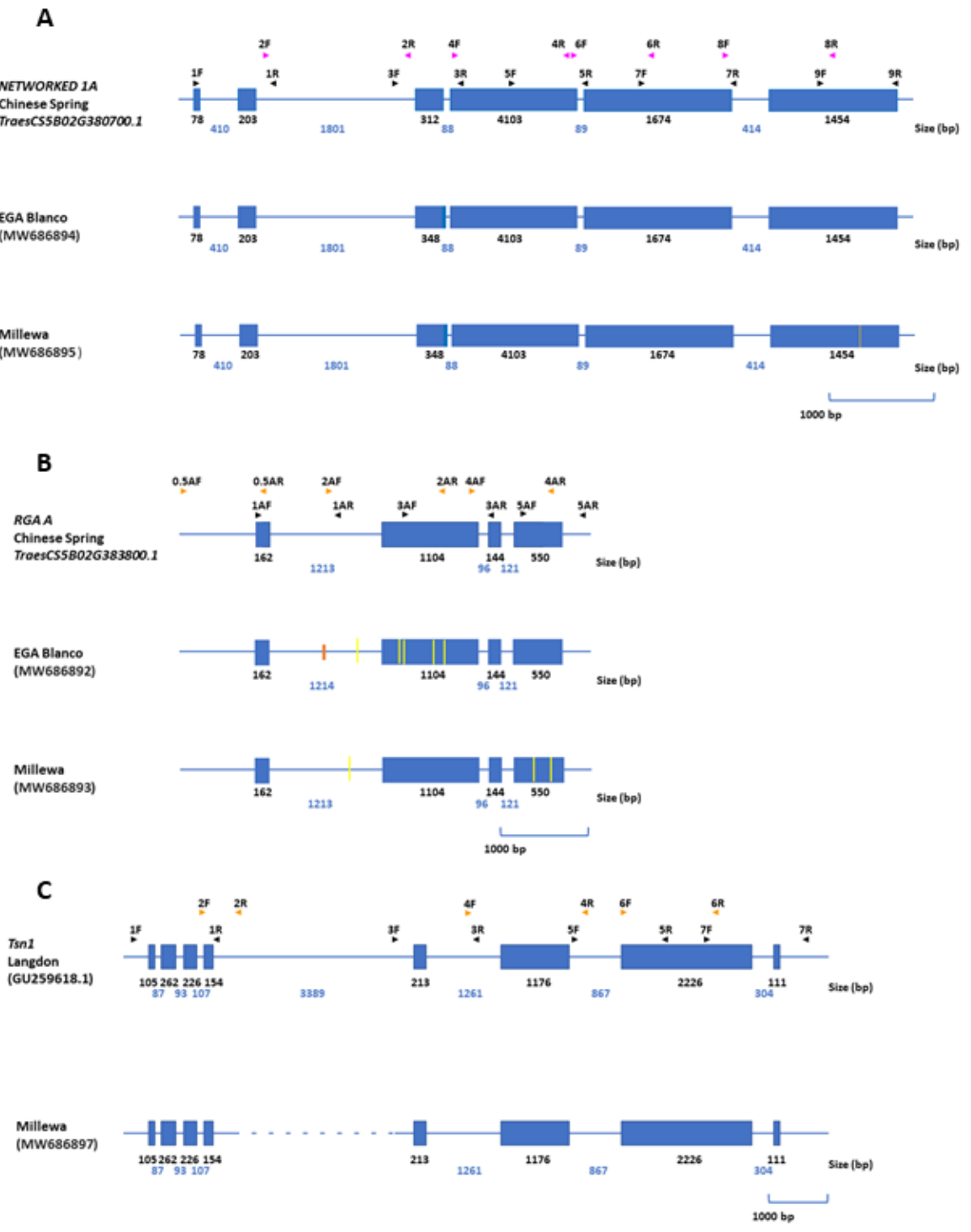

D
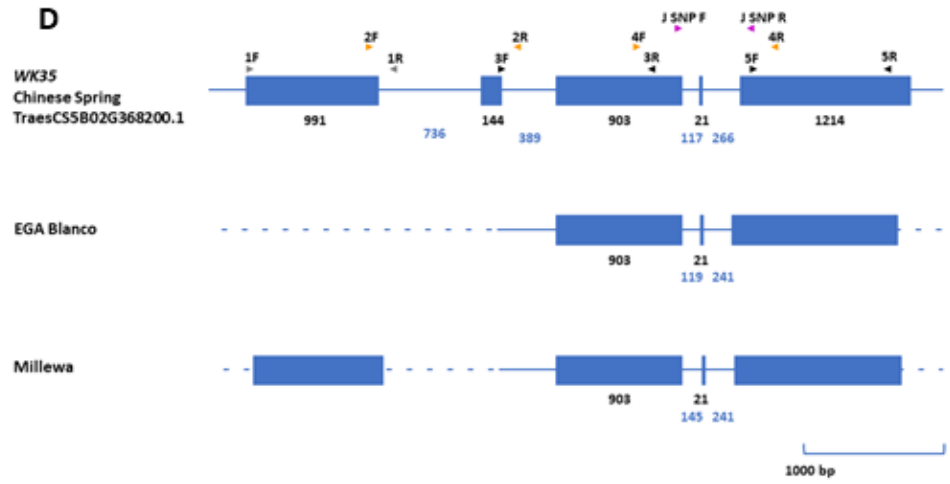

Figure 4. Gene structure for (A) NETWORKED 1A, (B) RGA A, (C) Tsn1 and (D) Wk35 on chromosome 5BL from reference sequence and varieties. Blue lines and boxes represent introns and exons, respectively, for annotated genes from reference sequences. Position of PCR primers for amplifying tiling paths from varieties are shown above gene structure from the reference sequences. Size of introns and exons are shown in base pairs (bp). Dashed blue lines represent regions where tiling paths were unable to be amplified in corresponding varieties. Yellow and orange lines represent SNP and INDELS, respectively, between reference sequences and varieties. Genbank accession numbers for complete annotated genes are provided in parentheses. 
The sequence difference between EGA Blanco and Millewa for NETWORK1A was subtle, with only one SNP identified in exon 6 (Figure 4A) whereas RGA identified six SNPs and an INDEL of $1 \mathrm{bp}$ in intron 1 between EGA Blanco and Millewa (Figure 4B). The inability to amplify tiling paths for Tsn1 confirmed the gene was deleted in EGA Blanco (Figure 4C) whereas only partial sequence was available for WK35 indicating considerable gene variation between EGA Blanco and Millewa (Figure 4D).

\section{Discussion}

The availability of high-density SNP array and high-quality reference genome sequence provided a foundation to compare genetic and physical maps for the QTL intervals on chromosomes $1 \mathrm{BS}$ and 5BL as a means to identify underlying candidate $R$-genes associated with SNB response. Neither EGA Blanco nor Millewa contained known alien translocated segments in their genomes determined by PCR analysis for species-specific repetitive sequences (data not shown), therefore, small scale translocations between genomes of EGA Blanco and Millewa with respect to the reference genome are likely to reflect intrachromosomal rearrangements during domestication of these Australian cultivars. Cytogenetic analysis [34,35] and high-density SNP arrays identified significant large and small translocations, deletions and inversions in different cultivars and breeding lines when compared with the reference genome sequence [32,35], and postulated that chromosome rearrangements and complex breeding histories provided lineage divergence for selective advantages in diverse environments. In contrast, the alignment of markers between genetic and physical maps for the region on 5BL did not detect large-scale chromosomal rearrangements between genomes of EGA Blanco, Millewa and the Chinese Spring reference sequence, indicating that some regions of genomes may harbour smaller structural variants or more conserved regions required for selective adaptation of modern varieties to broader environments. It is now becoming increasingly evident that structural variants, whether large or small-scale (including CNV and PAV), between genomes of breeding lines are associated with responses to biotic and biotic stresses [36].

Small structural variants such as CNV and PAV were common between the genome of the Chinese Spring reference sequence and cultivars EGA Blanco and Millewa. Multiple copies of $R$-gene families on chromosome 1BS and 5BL indicated that gene duplication was evident during the evolution of Chinses Spring reference genome, with opportunities to explore representation of specific gene family members and variation between the two Australian cultivars within QTL regions for SNB response. Despite the presence or absence of markers to specific regions for 13 and $12 R$-gene members around QTL on $1 B S$ and $5 \mathrm{BL}$, respectively, it was inconclusive whether the nature of structural variants between the reference sequence and the genomes of both cultivars represented entire gene loss or gain, insertion/deletions (INDEL) of specific gene regions or significant sequence diversity at PCR primer sites that precluded successful amplification of tiling paths. Nevertheless, it appeared there is significant structural variation for genes within and flanking QTL between EGA Blanco and Millewa. Recent evidence for high rates of homologous gene duplication and deletion events for members of the Bowman-Birk inhibitor gene family across varieties examined from pan-genomes [37] is testament to the dynamic nature of the wheat genome, leading to gene diversification and adaptability against biotic and abiotic stress during domestication and breeding.

This study further explored the diversification of specific gene copies between the reference sequence and genomes of EGA Blanco and Millewa for eight genes associated with SNB response on 1BS and 5BL. The lack of amplification of all tiling paths for five of the eight genes in either EGA Blanco or Millewa made it reasonable to assume that whole genes representing NRC1a (TraesCS1B02G002400.1), RGA (TraesCS1B02G003100.1), Snn1 (TraesCS1B02G004100.1) and TFIID (TraesCS1B02G007800.1) on 1BS and Tsn1 (GU259618.1) on 5BL were deleted in some varieties during domestication and breeding. Genes that were retained in only one cultivar (except Snn1) or in both, such as WK35 (TraesCS5B02G368200.1), only had regions with high identity to corresponding genes on 1BS and 5BL in the reference 
sequence, whereas NETWORKED 1A (TraesCS5B02G380700.1) and RGA A (TraesCS5B02G38 3800.1) were retained in both cultivars with subtle rearrangements. Therefore, it appeared that continual evolution during domestication from a common progenitor line resulted in an array of gene rearrangements across the two cultivars and the reference sequence. Rearrangements included an assortment of PAV, INDEL and SNP. There is increasing evidence that intrachromosomal variation between wheat varieties are common and gene sequences in breeding lines may not be represented in Chinese Spring [31,32,35,38], highlighting the limitations of using a single reference sequence to obtain a complete functional gene complement across breeding lines and cultivars. Therefore, it is possible that additional gene candidates within the QTL on 1BS and 5BL other than those identified in this study were represented in EGA Blanco and Millewa but not in Chinese Spring. In that regard, presence of the Tsn1 gene in Millewa but absent from the corresponding region in Chinese spring exemplify limitations when using a single reference sequence to identify genes controlling trait variation within QTL intervals in breeding lines and cultivars. Therefore, research efforts are moving from relying on a single reference genome in crop species to resequencing multiple accessions in an attempt to capture a wider repertoire of gene diversity as a pan-genome [36,39]. A complete genome sequence for EGA Blanco and Millewa will add to the wheat pan-genome [31,32] and further contribute towards identifying the entire functional gene complement controlling SNB response on 1BS and 5BL.

High-density SNP markers were unable to discriminate QTL controlling foliar SNB on 1BS, so it was presumed that similar genes responded to SNB foliar infection in at least two environments [33]. However, increasing genetic mapping density within the QTL interval using $R$-gene markers in the EGA Blanco and Millewa DH population determined that two distinct QTL reside on 1BS where SNB response appear to be controlled by different genes $\sim 7 \mathrm{cM}$ apart. Environment-specific QTL is consistent with recent reports for foliar SNB response on $1 \mathrm{~B}$ and other wheat chromosomes based on disease evaluation in different WA locations [7] and other regions of the world [10,40]. Interestingly, Snn1 [14,15] was only associated with QTL in 2008 (QSnl08.daw-1B) but not in 2007, indicating variability in SnTox1-Snn1 interactions in WA environments, similar to that reported for SnToxA-Tsn1 interactions on 5BL [6,7]. We expected that marker intervals for linked QTL on 5BL would be reduced using gene markers, however, the number of $R$-genes relative to the total gene content in the annotated regions of the reference sequence was significantly lower on $5 \mathrm{BL}$ than 1BS (8.7\% and 27.2\%, respectively). All 39 R-genes from a total of 448 genes on 5BL were investigated for marker development but none were identified as polymorphic (PAV, INDEL or SNP) for association analysis within the QSnl07.daw-5B region. Analysis of the entire functional gene complement by whole genome sequence of EGA Blanco and Millewa would provide further information on $R$-genes not represented in the reference sequence, if any, that may be associated with QSnl07.daw-5B and, indeed, QSnl08.daw-5B.

Quantitative plant disease resistance is a complex multicomponent system [41] so it is expected that a range of genes associated with SNB response are likely to involve components of biochemical, cellular and molecular pathways. Despite the unlikelihood of an entire functional gene complement being identified on 1BS and 5BL using a single reference sequence, a number of genes other than Tsn1, WK35 and Snn1 [15,24] were identified which allowed further insights into alternative biological mechanisms. Disease resistance gene analogues (RGA) represent broad gene families including NBS-LRR and transmembrane-LRR, both of which contain a number of classes and sub-classes ubiquitous in plant genomes that function directly in binding effector proteins or modifying host proteins to activate a cascade of signal transduction pathways [42]. The association of diverged copies of RGA genes on $1 \mathrm{BS}$ and 5BL indicated functional variation related to pathogen recognition or other signalling pathways in response to SNB in different environments, but an accurate prediction of their role in that regard is yet to be determined. Whole genome sequence of EGA Blanco and Millewa will provide further evolutionary clues leading towards unravelling functional significance of those variants. Likewise, genes related to signalling pathways were extended to include NRC1 that encode critical protein 
nodes for pattern and effector mediated signalling for cell death in response to pathogen infection [43-46]. The significance of either diverged or deleted RGA and NRC1 genes for mediating signalling pathways in environment-specific SNB response is not yet apparent but warrants further experimental investigation.

Signal transduction pathways also include those involved at the intracellular-extracell ular boundary during fungal infection $[27,47]$, with evidence that genes associated with SNB may be involved through basal defence mechanisms. NETWORKED $1 A$ is a multigene family encoding actin-binding proteins to form endoplasmic reticulum and plasma membrane complexes that react to extracellular signals, including biotic stresses [48,49]. Subtle variation of a member of the NETWORKED $1 A$ gene between resistant (EGA Blanco) and susceptible (Millewa) varieties may lead to protein differences that mediate actinmembrane interactions at the plasma membrane-cell wall interface after fungal infection influencing pathogen spread and onset of disease. The specific role of proteins encoded by NETWORKED $1 A$ alleles would shed further light on possible function for components of basal defence mechanisms in reducing or enhancing SNB disease progression.

Plant response to pathogen infection relies on complex mechanisms of gene regulation for components of pathogen recognition, signal transduction and defence. The TFIID gene associated with SNB response on 1BS indicated molecular elements may regulate pathogen infection and disease response through specific gene expression in biochemical and cellular pathways. TFIID recognise and bind to core promoter elements (generally TATA boxes) in a complex assembly of transcription machinery that interact with co-factors, gene-specific activators and repressors for certain levels of transcriptional output [50,51]. Knowledge on specific roles for TFIID in plant disease response is limited but differential gene expression in response to crown rot in wheat [52] and association with Cercospora leaf spot disease in QTL mapping in mungbean [53] indicated that variation in TFIID may regulate transcriptional activity for specific genes of disease response pathways. However, further knowledge is required on the specific genes regulated by TFIID and how sequence variation contributes to pathogen recognition, signal transduction and defence towards eliciting an SNB response.

Although structural variation exists between hexaploid wheat genomes of different origins, exploitation of the wheat reference sequence in this study provided a preliminary basis to target some, but unlikely all, genes controlling SNB response. Identifying the full complement of functional genes would require resequencing genomes of EGA Blanco, Millewa and indeed, other modern varieties and breeding lines contributing towards a pangenome that will unravel the complex functional and coordinated roles of biochemical, cellular and molecular mechanisms that elicit a disease response when wheat is challenged with diverse SNB isolates in a specific environment.

\section{Materials and Methods}

\subsection{Plant Material and Evaluation for SNB Response}

The DH population consisting of 241 lines developed from EGA Blanco/Millewa and phenotypic evaluation in two environments at South Perth, Western Australia, in 2007 and 2008, as previously described [6], was accessed from the grains collection at the Department of Primary Industries and Regional Development. Details of mixed isolates used at both locations, trial designs and methodology for inoculation and evaluating disease response, phenotypic and statistical analysis of parents and individuals from the EGA Blanco/Millewa DH population and QTL detection using mean plot values for each individual were previously described [6]. Mean plot SNB scores from 2007 and 2008 disease evaluation [6] were used for QTL analysis in this study to identify genes associated with SNB response. Genotyping data and map construction with high-density SNP markers was previously described [33]. 


\subsection{Aligning Genetic and Physical Maps and Annotation of Gene Content}

The genetic map and QTL intervals for SNB resistance on chromosomes 1BS and 5BL [33] were aligned with the whole genome assembly of bead wheat (Refseq v1.0) through the IWGSC database (Gramene release \#62 November 2019 at http: / / www.gramene.org accessed on 24 April 2021). DNA sequence of SNP markers within and flanking each QTL on chromosomes 1B and 5B (Figure 1) were used as query in BLASTN analysis. Hits having $>99 \%$ identity with sequences in the reference genome demarcated the physical interval for each QTL. Prediction of coding and non-coding genes within the physical interval were accessed from the de novo wheat genome assembly and further annotated using BLASTP and SmartBLAST alignment against database repository from NCBI (https: / /blast.ncbi.nlm.nih.gov / Blast.cgi accessed on 24 April 2021). Protein similarity was determined with an amino acid identity threshold of $>50 \%$ identity for $>50 \%$ sequence coverage $\left(e\right.$ value $\left.<10^{-5}\right)$. Genes encoding proteins having amino acid identity to known disease resistance genes, disease resistance gene motifs or defence response pathways were considered as candidate $R$-genes (Supplementary Table S1).

\subsection{Primer Design and Tiling Paths}

Sequences from each of the candidate genes within physical intervals from either chromosome 1BS or 5BL were extracted and subjected to BLASTN of the whole genome assembly (Gramene release \#62 November 2019 at http: / / www.gramene.org accessed on 24 April 2021) to identify homologs on the A, B and D genomes. DNA sequence alignment of gene homologs identified sub-genome specific sequence variants and PCR primers were designed to target genome and allele specific polymorphisms tiled across the total available sequence from the reference genome cv Chinese Spring IWSGC Refseq v1.0. PCR primers were designed for amplicons using Primer3Plus [54] to have a minimum tiling overlap of $100 \mathrm{bp}$. Primer sequences for tiling paths of selected genes are summarised in Supplementary Table S1.

\subsection{PCR Amplification and Sequencing of Genomic Tiling Paths}

PCR amplification was carried out in a $10 \mu \mathrm{l}$ reaction volume containing $50 \mathrm{ng}$ genomic DNA, 1U Taq DNA polymerase (Meridian Bioscience, Cincinnati, OH, USA), $0.15 \mathrm{mM}$ dNTP (Meridian Bioscience, Cincinnati, USA), $1 \mu \mathrm{M}$ primers (Macrogen Inc. Seoul, South Korea). Amplification was performed on a thermocycler (Applied Biosystems, Foster City, CA, USA) under the following conditions: 1 cycle $95^{\circ} \mathrm{C}$ for $3 \mathrm{~min}, 5$ cycles of $95^{\circ} \mathrm{C}$ for $30 \mathrm{~s}, 65-55^{\circ} \mathrm{C}$ (primer dependent) $30 \mathrm{~s}, 72{ }^{\circ} \mathrm{C}$ for $1 \mathrm{~min}$, decreasing $1{ }^{\circ} \mathrm{C}$ per cycle followed by 30 cycles of $95{ }^{\circ} \mathrm{C}$ for $1 \mathrm{~min}, 60-50{ }^{\circ} \mathrm{C}$ (primer dependent) $30 \mathrm{~s}, 72{ }^{\circ} \mathrm{C}$ for $1 \mathrm{~min}$ with a final extension at $72{ }^{\circ} \mathrm{C}$ for $5 \mathrm{~min}$. PCR products were separated on a $2 \%$ agarose gel via electrophoresis and visualised under UV light using 1X GelGreen (Biotium, Fremont, CA, USA). PCR amplifications were performed using genomic DNA extracted from the experimental line Chinese Spring and cultivars 'EGA Blanco' and 'Millewa'. Genome and chromosome specificity for each candidate gene was confirmed using at least one amplicon from a tiling path when DNA from Chinese Spring and nulli-tetrasomic lines for chromosomes 1A, 1B, 1D, 5A, 5B and 5D [55] were used as a template in the PCR reaction.

Amplicons of tiling paths from cultivars EGA Blanco and Millewa were either directly sequenced or cloned into the pGEM-T easy vector system (Promega, Madison, WI, USA) following manufacturer's instructions and sequenced using capillary electrophoresis sequencing (Macrogen Inc.). A minimum of three independent PCR reactions or cloned products was sequenced for each PCR product.

\subsection{Gene Marker Development, Genotyping and QTL Analysis}

PCR amplicons from tiling paths which resulted in a PAV between EGA Blanco and Millewa were directly mapped as candidate gene markers. The remaining tiling paths conserved between EGA Blanco and Millewa were then sequenced to identify SNP for the use in marker development. 
Individuals from the EGA Blanco/Millewa DH population were genotyped for candidate gene markers (PAV or SNP-based marker) and integrated with the genetic map totalling 13,308 markers merged from the 90K iSelect SNP array, DArT and SSR marker sets, as previously described [33,56]. Candidate gene markers with less than $80 \%$ call rate or segregation distortion ( $p$-value $>0.10$ calculated from a $\chi 2$ test), samples with a high crossover rate (indicating a mixed sample) or duplicate samples ( $>95 \%$ identical genotypes) were removed from the analysis. Individuals of the $\mathrm{DH}$ population were also genotyped for diagnostic markers Xfcp623, Xfcp620 and X3476283 for genes Tsn1, WK35 [24] and Snn1 [15], respectively. Genetic map construction was realized using QTL IciMapping Version 4.0.6.0 [57] to determine marker order.

QTL IciMapping was used for inclusive composite interval mapping with additive effect (ICIM-ADD) using mean foliar infection scores collected at South Perth, Western Australia in 2007 and 2008, as previously described [6]. Redundant markers were removed by selecting the BIN parameter within QTL IciMapping using "Delete redundancy By Missing Rate (\%)" and missing data were set at $20 \%$ using the "Delete markers By missing rate (\%)" function. MAP parameters were set at LOD6, specifying Algorithm: nnTwoOpt and Rippling:SARF. Parameters for all environments were set to $0.1 \mathrm{cM}$ steps, Probability in Stepwise Regression (PIN) of 0.001, minimum LOD threshold of 2.5, and deleting missing phenotypes. Final maps and associated QTL were drawn using MapChart Version 2.3 [58] and QTL IciMapping.

\subsection{Gene Structure Analysis}

DNA sequence of tiling paths amplified from wheat cultivars EGA Blanco and Millewa were assembled using Geneious R10 (https: / / www.geneious.com accessed on 24 April 2021, San Diego, CA, USA) and aligned with corresponding gene sequence annotations retrieved from the whole genome assembly (Refseq v1.0) with $>95 \%$ identity confirmed from BLASTN analysis.

Supplementary Materials: The following are available online at https://www.mdpi.com/article/10 .3390/ijms22115580/s1, Table S1: Gene annotation on the QTL intervals on chromosomes 1BS and $5 \mathrm{BL}$ and primer sequence for selected $R$-genes.

Author Contributions: Conceptualization, D.L., E.W. and M.F.; methodology, D.L., E.W. and M.F.; formal analysis, D.L., E.W. and M.F.; investigation, D.L., E.W. and M.F.; data curation, D.L. and E.W.; writing—original draft preparation, M.F.; writing—review and editing, D.L., E.W. and M.F.; supervision, M.F.; project administration, M.F.; funding acquisition, M.F. All authors have read and agreed to the published version of the manuscript.

Funding: This research was funded by Grains Research and Development Corporation, grant number DAW00248.

Institutional Review Board Statement: Not applicable.

Informed Consent Statement: Not applicable.

Data Availability Statement: The data presented in this study are available on request from the corresponding author.

Conflicts of Interest: The authors declare no conflict of interest. The funders had no role in the design of the study; in the collection, analyses, or interpretation of data; in the writing of the manuscript, or in the decision to publish the results.

\section{References}

1. Murray, G.M.; Brennan, J.P. Estimating disease losses to the Australian wheat industry. Australas. Plant Pathol. 2009, 38, 558-570. [CrossRef]

2. Mullaney, E.J; Scharen, A.L.; Bryan, M.D. Resistance to Septoria nodorum in a durum wheat cultivar as determined by stage of host development. Can. J. Bot. 1983, 61, 2248-2250. [CrossRef]

3. Spadafora, V.J; Cole, H.; Frank, J.A. Effects of leaf and glume blotch caused by Leptosphaeria nodorum on yield and yield components of soft red winter wheat in Pennsylvania. Phytopathology 1987, 77, 1326-1329. [CrossRef] 
4. Wainshilbaum, S.J.; Lipps, P.E. Effect of temperature and growth stage of wheat on development of leaf and glume blotch caused by Septoria tritici and S. nodorum. Plant Dis. 1991, 75, 993-998. [CrossRef]

5. Shankar, M.; Walker, E.; Golzar, H.; Loughman, R.; Wilson, R.E.; Francki, M.G. Quantitative Trait Loci for Seedling and Adult Plant Resistance to Stagonospora nodorum in Wheat. Phytopathology 2008, 98, 886-893. [CrossRef] [PubMed]

6. Francki, M.G.; Shankar, M.; Walker, E.; Loughman, R.; Golzar, H.; Ohm, H. New Quantitative Trait Loci in Wheat for Flag Leaf Resistance to Stagonospora nodorum Blotch. Phytopathology 2011, 101, 1278-1284. [CrossRef]

7. Francki, M.G.; Walker, E.; McMullan, C.J.; Morris, W.G. Multi-Location Evaluation of Global Wheat Lines Reveal Multiple QTL for Adult Plant Resistance to Septoria Nodorum Blotch (SNB) Detected in Specific Environments and in Response to Different Isolates. Front. Plant Sci. 2020, 11, 771. [CrossRef]

8. Lu, Q.; Lillemo, M. Molecular mapping of adult plant resistance to Parastogonospora nodorum leaf blotch in bread wheat lines 'Shanghai-3/Catbird' and 'Naxos'. Theor. Appl. Genet. 2014, 127, 2635-2644. [CrossRef]

9. Ruud, A.K.; Dieseth, J.A.; Ficke, A.; Furuki, E.; Phan, H.T.T.; Oliver, R.P.; Tan, K.; Lillemo, M. Genome-Wide Association Mapping of Resistance to Septoria Nodorum Leaf Blotch in a Nordic Spring Wheat Collection. Plant Genome 2019, 12, 180105. [CrossRef]

10. Lin, M.; Corsi, B.; Ficke, A.; Tan, K.-C.; Cockram, J.; Lillemo, M. Genetic mapping using a wheat multi-founder population reveals a locus on chromosome $2 \mathrm{~A}$ controlling resistance to both leaf and glume blotch caused by the necrotrophic fungal pathogen Parastagonospora nodorum. Theor. Appl. Genet. 2020, 133, 785-808. [CrossRef] [PubMed]

11. McDonald, M.C.; Solomon, P.S. Just the surface. Advances in the discovery and characterization of necrotrophic wheat effectors. Curr. Opin. Microbiol. 2018, 46, 14-18. [CrossRef] [PubMed]

12. Liu, Z.; Friesen, T.L.; Ling, H.; Meinhardt, S.W.; Oliver, R.P.; Rasmussen, J.B.; Faris, J.D. The Tsn1-ToxA interaction in the wheat-Stagonospora nodorum pathosystem parallels that of the wheat-tan spot system. Genome 2006, 49, 1265-1273. [CrossRef] [PubMed]

13. Friesen, T.L.; Chu, C.-G.; Liu, Z.H.; Xu, S.S.; Halley, S.; Faris, J.D. Host-selective toxins produced by Stagonospora nodorum confer disease susceptibility in adult wheat plants under field conditions. Theor. Appl. Genet. 2009, 118, 1489-1497. [CrossRef] [PubMed]

14. Phan, H.T.T.; Ryback, K.; Furuki, E.; Breen, S.; Solomon, P.S.; Oliver, R.P.; Tan, K.C. Differential effector expression un-derpins epistasis in a plant fungal disease. Plant J. 2016, 87, 343-354. [CrossRef] [PubMed]

15. Shi, G.; Zhang, Z.; Friesen, T.L.; Raats, D.; Fahima, T.; Brueggeman, R.S.; Lu, S.; Trick, H.N.; Liu, Z.; Chao, W.; et al. The hijacking of a receptor kinase-driven pathway by a wheat fungal pathogen leads to disease. Sci. Adv. 2016, 2, e1600822. [CrossRef]

16. Ruud, A.K.; Wingju, S.; Belova, T.; Friesen, T.L.; Lillemo, M. Mapping of SnTox3-Snn3 as a major determinant of field susceptibility to Septoria nodorum leaf blotch in the SHA3/CBRD $\times$ Naxos population. Theor. Appl. Genet. 2017, 130, 1361-1374. [CrossRef]

17. Downie, R.C.; Bouvet, L.; Furuki, E.; Gosman, N.; Gardner, K.A.; Mackay, I.J.; Mantello, C.C.; Mellers, G.; Phan, H.T.T.; Rose, G.A.; et al. Assessing European Wheat Sensitivities to Parastagonospora nodorum Necrotrophic Effectors and Fine-Mapping the Snn3-B1 Locus Conferring Sensitivity to the Effector SnTox3. Front. Plant Sci. 2018, 9, 881. [CrossRef] [PubMed]

18. Abeysekara, N.S.; Friesen, T.L.; Keller, B.; Faris, J.D. Identification and characterization of a novel host-toxin interaction in the wheat-Stagonospora nodorum pathosystem. Theor. Appl. Genet. 2009, 120, 117-126. [CrossRef]

19. Friesen, T.L.; Chu, C.; Xu, S.S.; Faris, J.D. SnTox5-Snn5: A novel Stagonospora nodorum effector- wheat gene interaction and its relationship with SnToxA-Tsn1 and SnTox3-Snn3-B1 interactions. Mol. Plant Path. 2012, 13, 1101-1109. [CrossRef]

20. Gao, Y.; Faris, J.D.; Liu, Z.; Kim, Y.M.; Syme, R.A.; Oliver, R.P.; Xu, S.S.; Friesen, T.L. Identification and Characterization of the SnTox6-Snn6 Interaction in the Parastagonospora nodorum-Wheat Pathosystem. Mol. Plant-Microbe Interact. 2015, 28, 615-625. [CrossRef]

21. Shi, G.; Friesen, T.L.; Saini, J.; Xu, S.S.; Rasmussen, J.B.; Faris, J.D. The wheat Snn7 gene confers susceptibility on recog-nition of the Parastagonospora nodorum necrotrophic effector SnTox7. Plant Genome 2015, 8, 2. [CrossRef] [PubMed]

22. Gonzalelz-Hernandez, J.L.; Singh, P.K.; Mergoum, M.; Adhikari, T.B.; Kianian, S.F.; Simsek, S.; Elias, E.M. A quantitative trait locus on chromosome 5B controls resistance of Triticum turgidum (L.) var. diccocoides to Stagnospora nodorum blotch. Euphytica 2009, 166, 199-206. [CrossRef]

23. Cowger, C.; Ward, B.; Brown-Guedira, G.; Brown, J.K.M. Role of Effector-Sensitivity Gene Interactions and Durability of Quantitative Resistance to Septoria Nodorum Blotch in Eastern U.S. Wheat. Front. Plant Sci. 2020, 11, 155. [CrossRef] [PubMed]

24. Faris, J.D.; Zhang, Z.; Lu, H.; Lu, S.; Reddy, L.; Cloutier, S.; Fellers, J.P.; Meinhardt, S.W.; Rasmussen, J.B.; Xu, S.S.; et al. A unique wheat disease resistance-like gene governs effector-triggered susceptibility to necrotrophic pathogens. Proc. Natl. Acad. Sci. USA 2010, 107, 13544-13549. [CrossRef]

25. Jones, J.D.G.; Dangl, J.L. The plant immune system. Nature 2006, 444, 323-329. [CrossRef] [PubMed]

26. Loreng, J. Necrotrophic exploitation abs subversion of plant defense: A lifestyle or just a phase, and implications in breeding. Phytopathology 2019, 109, 332-346. [CrossRef]

27. Bellincampi, D.; Cervone, F.; Lionetti, V. Plant cell wall dynamics and wall related susceptibility in plant-pathogen interactions. Front. Plant Sci. 2014, 5, 228. [CrossRef]

28. The International Wheat Genome Sequencing Consortium. A chromosome-based draft sequence of the hexaploid bread wheat (Triticum aestivum) genome. Science 2014, 345, 6194.

29. The International Wheat Genome Sequencing Consortium. Shifting the limits of wheat research and breeding using a fully annotated reference genome. Science 2018, 361, 6430. 
30. Clavijo, B.; Venturini, L.; Schudoma, C.; Garcia, A.G.; Kaithakottil, G.; Wright, J.; Borrill, P.; Kettleborough, G.; Heavens, D.; Chapman, H.; et al. An improved assembly and annotation of the allohexaplod wheat genome identifies complete families of agronomic genes and provides genomic evidence for chromosomal translocations. Genome Res. 2017, 27, 885-896. [CrossRef]

31. Montenegro, J.D.; Golicz, A.A.; Bayer, P.E.; Hurgobin, B.; Lee, H.; Chan, C.-K.K.; Visendi, P.; Lai, K.; Doležel, J.; Batley, J.; et al. The pangenome of hexaploidy bread wheat. Plant J. 2017, 90, 1007-1013. [CrossRef] [PubMed]

32. Walkowiak, S.; Gao, L.; Monat, C.; Haberer, G.; Kassa, M.T.; Brinton, J.; Ramirez-Gonzalez, R.H.; Kolodziej, M.C.; Delorean, E.; Thambugala, D.; et al. Faculty Opinions recommendation of Multiple wheat genomes reveal global variation in modern breeding. Nature 2020, 588, 277. [CrossRef] [PubMed]

33. Francki, M.G.; Walker, E.; Li, D.A.; Forrest, K. High-density SNP mapping reveals closely linked QTL for resistance to Stagonospora nodorum blotch (SNB) in flag leaf and glume of hexaploid wheat. Genome 2018, 61, 145-149. [CrossRef] [PubMed]

34. Badaeva, E.D.; Dedkova, O.S.; Gay, G.; Pukhalskyi, V.A.; Zelenin, A.V.; Bernard, S.; Bernard, M. Chromosomal rear-rangements in wheat: Their types and distribution. Genome 2007, 50, 907-926. [CrossRef]

35. Przewieslik-Allen, A.M.; Wilkinson, P.A.; Burridge, A.J.; Winfield, M.O.; Dai, X.; Beaumont, M.; King, J.; Yang, C.-Y.; Griffiths, S.; Wingen, L.U.; et al. The role of gene flow and chromosomal instability in shaping the bread wheat genome. Nat. Plants 2021, 7, 172-183. [CrossRef] [PubMed]

36. Tao, Y.; Zhao, X.; Mace, E.; Henry, R.; Jordan, D. Exploring and Exploiting Pan-genomics for Crop Improvement. Mol. Plant 2019, 12, 156-169. [CrossRef] [PubMed]

37. Xie, Y.; Ravet, K.; Pearce, S. Extensive structural variation in the Bowman-Birk inhibitor family in common wheat (Triticum aestivum L.). BMC Genom. 2021, 22, 1-21. [CrossRef]

38. Liu, M.; Stiller, J.; Holušová, K.; Vrána, J.; Liu, D.; Doležel, J.; Liu, C. Chromosome-specific sequencing reveals an extensive dispensable genome component in wheat. Sci. Rep. 2016, 6, 36398. [CrossRef]

39. Della, C.R.; Qiu, Y.; Ou, S.; Hufford, M.B.; Hirsch, C.N. How the pan-genome is changing crop genomics and improvement. Genome Biol. 2021, 22, 3. [CrossRef]

40. Czembor, P.C.; Arseniuk, E.; Radecka-Janusik, M.; Piechota, U.; Słowacki, P. Quantitative trait loci analysis of adult plant resistance to Parastagonospora nodorum blotch in winter wheat cv. Liwilla (Triticum aestivum L.). Eur. J. Plant Pathol. 2019, 155, 1001-1016. [CrossRef]

41. Andersen, E.J.; Nepal, M.P.; Purintun, J.M.; Nelson, D.; Mermigka, G.; Sarris, P.F. Wheat Disease Resistance Genes and Their Diversification Through Integrated Domain Fusions. Front. Genet. 2020, 11, 898. [CrossRef] [PubMed]

42. Sekhwar, M.K.; Li, P.; Lam, I.; Wang, X.; Cloutier, S.; You, F.M. Disease resistance gene analogues (RGAs) in plants. Int. J. Mol. Sci. 2015, 16, 19248-19290. [CrossRef] [PubMed]

43. Baggs, E.; Dagdas, G.; Krasileva, K. NLR diversity, helpers and integrated domains: Making sense of the NLR IDentity. Curr. Opin. Plant Biol. 2017, 38, 59-67. [CrossRef] [PubMed]

44. Leibman-Markus, M.; Pizarro, L.; Bar, M.; Coaker, G.; Avni, A. NRC proteins-A critical node for pattern and effector mediated signaling. Plant Signal. Behav. 2018, 13, 1-4. [CrossRef] [PubMed]

45. Wu, C.; Belhaj, K.; Bozkurt, T.O.; Birk, M.S.; Kamoun, S. Helper NLR proteins NRC 2a/b and NRC 3 but not NRC 1 are required for Pto-mediated cell death and resistance in Nicotiana benthamiana. New Phytol. 2016, 209, 1344-1352. [CrossRef]

46. Wu, C.-H.; Abd-El-Haliem, A.; Bozkurt, T.O.; Belhaj, K.; Terauchi, R.; Vossen, J.H.; Kamoun, S. NLR network mediates immunity to diverse plant pathogens. Proc. Natl. Acad. Sci. USA 2017, 114, 8113-8118. [CrossRef] [PubMed]

47. Hückellhoven, R. Cell wall-associated mechanisms of disease resistance and susceptibility. Ann. Rev. Phytopathol. 2007, 45, 101-127. [CrossRef] [PubMed]

48. Deeks, M.J.; Calcutt, J.R.; Ingle, E.K.; Hawkins, T.J.; Chapman, S.; Richardson, A.C.; Mentlak, D.A.; Dixon, M.R.; Cartwright, F.; Smertenko, A.P.; et al. A Superfamily of Actin-Binding Proteins at the Actin-Membrane Nexus of Higher Plants. Curr. Biol. 2012, 22, 1595-1600. [CrossRef] [PubMed]

49. Wang, P.; Hawes, C.; Hussey, P.J. Plant Endoplasmic Reticulum-Plasma Membrane Contact Sites. Trends Plant Sci. 2017, 22, 289-297. [CrossRef]

50. Aoyagi, N.; Wassarman, D.A. Genes encoding Drosophila melanogaster RNA polymerase II general transcription factors: Diversity in TFIIA and TFIID components contributes to gene-specific regulation. J. Cell Biol. 2000, 150, F45-F49. [CrossRef]

51. Patel, A.B.; Greber, B.J.; Nogales, E. Recent insights into the structure of TFIID, its assembly and its binding to core promoter. Curr. Opin. Struct. Biol. 2020, 61, 17-24. [CrossRef]

52. Stephens, A.E.; Gardiner, D.M.; White, R.G.; Munn, A.L.; Manners, J.M. Phases of Infection and Gene Expression of Fusarium graminearum During Crown Rot Disease of Wheat. Mol. Plant-Microbe Interact. 2008, 21, 1571-1581. [CrossRef] [PubMed]

53. Yundaeng, C.; Somta, P.; Chen, J.; Yuan, X.; Chankaew, S.; Chen, X. Fine mapping of QTL conferring Cercospora leaf spot disease resistance in mungbean revealed TAF5 as candidate gene for the resistance. Theor. Appl. Genet. 2021, 134, 701-714. [CrossRef] [PubMed]

54. Untergasser, A.; Nijveen, H.; Rao, X.; Bisseling, T.; Geurts, R.; Leunissen, J.A.M. Primer3Plus, an enhanced web interface to Primer3. Nucleic Acids Res. 2007, 35, W71-W74. [CrossRef] [PubMed]

55. Sears, E. Nullisomic-tetrasomic combinations in hexaploid wheat. In Chromosome Manipulations and Plant Genetics; Lewis, D.R., Ed.; Oliver and Boyd: London, UK, 1966; pp. 29-47. 
56. Francki, M.G.; Walker, E.; Crawford, A.C.; Broughton, S.; Ohm, H.W.; Barclay, I.; Wilson, R.E.; McLean, R. Comparison of genetic and cytogenetic maps of hexaploid wheat (Triticum aestivum L.) using SSR and DArT markers. Mol. Genet. Genom. 2008, 281, 181-191. [CrossRef]

57. Meng, L.; Li, H.; Zhang, L.; Wang, J. QTL IciMapping: Integrated software for genetic linkage map construction and quantitative trait locus mapping in biparental populations. Crop. J. 2015, 3, 269-283. [CrossRef]

58. Voorrips, R.E. MapChart: Software for the Graphical Presentation of Linkage Maps and QTLs. J. Hered. 2002, 93, 77-78. [CrossRef] 